\title{
Experimental Study of a Radial Turbine Using Pitch-Controlled Guide Vanes for Wave Power Conversion
}

\author{
Manabu Takao, ${ }^{1}$ Yoshihiro Fujioka, ${ }^{1}$ Hiroki Homma, ${ }^{1}$ Tae-Whan Kim, ${ }^{2}$ and Toshiaki Setoguchi ${ }^{3}$ \\ ${ }^{1}$ Department of Mechanical Engineering, Matsue National College of Technology, 14-4 Nishiikuma-cho, Matsue-shi, \\ Shimane 690-8518, Japan \\ ${ }^{2}$ Department of Architectural Facility, Doowon Technical College, 678 Janwon-ri, Ansung-si, Kyongki 456-890, Korea \\ ${ }^{3}$ Department of Mechanical Engineering, Saga University, 1 Honjo-machi, Saga-shi, Saga 840-8502, Japan
}

Received 13 August 2005; Accepted 2 September 2005

\begin{abstract}
In order to develop a high-performance radial turbine for wave power conversion, a radial turbine with pitch-controlled guide vanes has been proposed and manufactured in the study. The proposed radial turbine has been investigated experimentally by model testing under steady and sinusoidal flow conditions. Then, the experimental results have been compared with those of the conventional radial turbine for wave power conversion, that is, a radial turbine with fixed guide vanes. As a result, the running characteristics of the proposed radial turbine under steady and sinusoidal flow conditions were clarified and the effect of diffuser setting angle of guide vane on the turbine characteristics was presented. Furthermore, it seems that the proposed radial turbine is much superior to the conventional radial turbine.
\end{abstract}

Copyright ( $) 2006$ Manabu Takao et al. This is an open access article distributed under the Creative Commons Attribution License, which permits unrestricted use, distribution, and reproduction in any medium, provided the original work is properly cited.

\section{INTRODUCTION}

The performance of radial flow turbines having low rotational speed and low noise level, which can be used for wave power conversion using the oscillating water column (OWC) principle, has been studied by a number of authors (Kaneko et al. [1, 2]; McCormick et al. [3]; McCormick and Cochran [4]; Veziroglu [5]). It was found that the efficiency of radial turbines using reaction-type rotor blading was extremely low (Kaneko et al. $[1,2]$ ). On the other hand, the efficiency of impulse blading is higher according to the studies (McCormick et al. [3]; McCormick and Cochran [4]). However, detailed performance characteristics of impulse-type radial turbines were not found in the literature. In an attempt to fill this gap, performance characteristics were measured on turbines (508.8 $\mathrm{mm}$ rotor diameter) with different guide vane geometries by the authors (Setoguchi et al. [6]; Takao et al. [7]). Performance was also measured for flow radially inward and outward through the turbine, which is made possible by an oscillatory flow rig. As a result, it was clarified by the experiment that the turbine efficiency of impulse blading was not so high because there are large differences between the absolute outlet flow angle and setting angle of the downstream guide vane, and the downstream guide vane does not work as a diffuser (Setoguchi et al. [6]; Takao et al. [7]).
In order to overcome the above drawback and enhance the performance of the radial turbine, the authors have proposed a radial turbine with pitch-controlled guide vanes for wave power conversion. The proposed radial turbine has been investigated experimentally by model testing under steady and sinusoidal flow conditions. Then, the experimental results have been compared with those of a radial turbine with fixed guide vanes.

\section{EXPERIMENTAL APPARATUS AND PROCEDURE}

The test rig consists of a large piston-cylinder, one end of which is followed by a settling chamber as shown in Figure 1. The radial turbine's axial entry/exit is attached to the settling chamber as shown in Figure 2. The piston can be driven back and forth inside the cylinder by means of three ball screws through three nuts fixed to the piston. All three screws are driven by a DC servomotor through chain and sprockets. A computer controls this motor and hence the piston velocity to produce any airflows (intermittently for short periods). The test turbine rotor shaft is coupled to the shaft of a servomotor generator through a torque transducer. The motorgenerator is electronically controlled such that the turbineshaft angular velocity is held constant at any set value. The flow rate through the turbine $Q$, whether it is inhalation (flow from the atmosphere into the rig) or exhalation (flow 


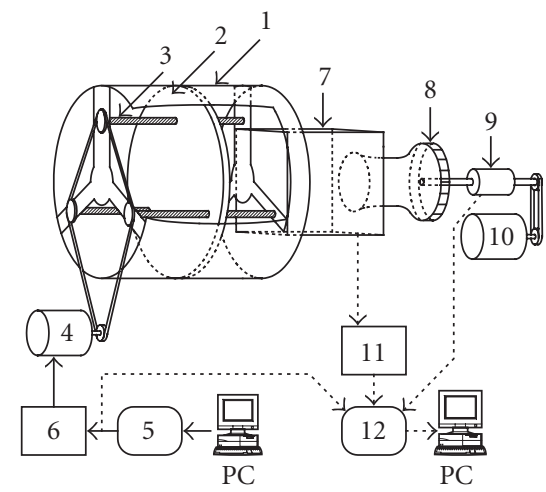

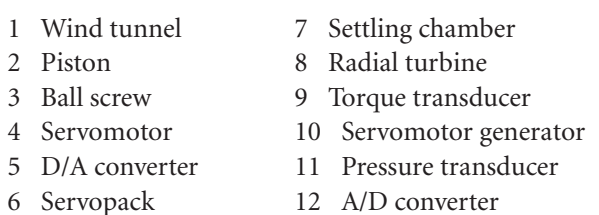

FIgURE 1: Test apparatus.

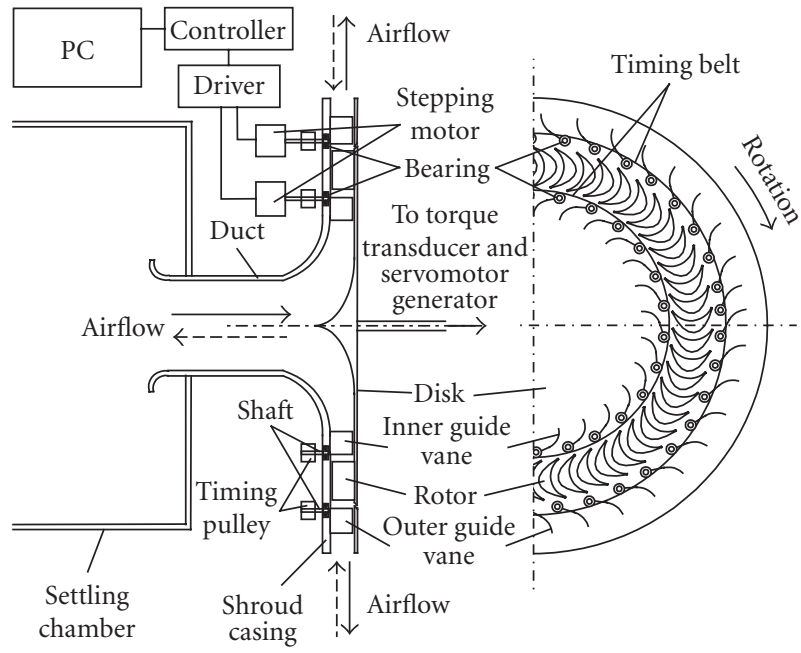

FIgURE 2: Radial turbine with pitch-controlled guide vanes.

from the rig to the atmosphere), is measured by Pitot tube survey. The radial flow velocity $v_{R}$ at mean radius $r_{R}$ in the turbine is calculated from $Q=A_{R} v_{R}$, where $A_{R}$ is the flow passage area at mean radius $\left(=2 \pi r_{R} h\right)$. In a typical test, for a particular turbine geometry, the volumetric flow rate $Q$, pressure difference between settling chamber and atmosphere $\Delta p$, turbine torque $T_{o}$, and turbine angular velocity $\omega$ are all recorded. Thereby, data for one flow coefficient $\phi$ defined in (3) are obtained. Data for a range of flow coefficients are collected by varying flow rate or turbine angular velocity. Tests were performed with turbine shaft angular velocities $\omega$ up to $68.1 \mathrm{rad} / \mathrm{s}$ and flow rates $Q$ up to $0.275 \mathrm{~m}^{3} / \mathrm{s}$. The Reynolds number based on the blade chord was approximately $3 \times 10^{4}$ at conditions corresponding to the peak efficiency of the turbine. The measurement uncertainty in efficiency is about $\pm 1 \%$.

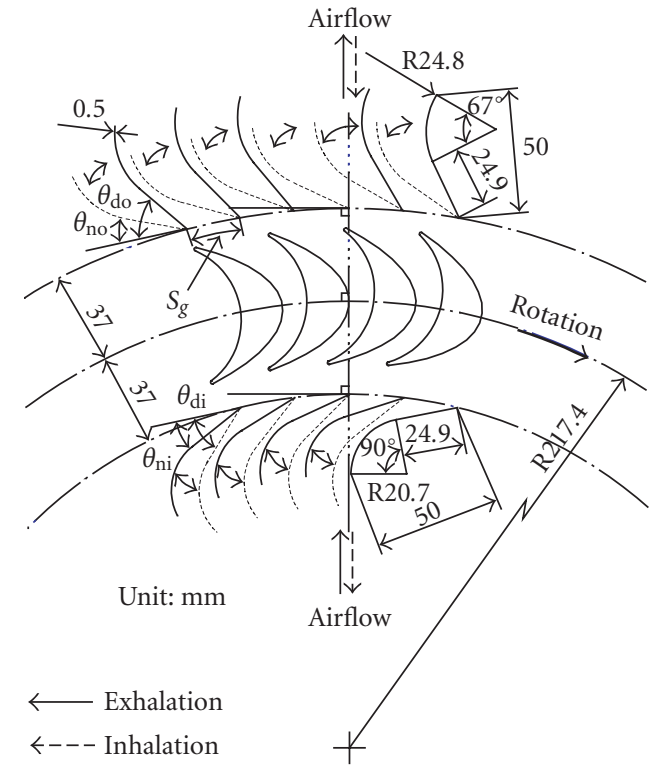

FIgURE 3: Configuration of turbine.

The radial turbine shown in Figure 2 was tested at a constant rotational speed in steady or sinusoidal airflow. The sign and magnitude of the torque of the motor generator are servo-controlled so as to hold the turbine speed constant even if the flow velocity is varying with time. The part of shroud casing and the part of disk covering the inner guide vane to the exit are flat and parallel to each other. The height of flow path of the turbine $h$ (gap between the shroud casing and the disk) is $44 \mathrm{~mm}$. The flow passage from inlet to inner guide vane entry has been shaped such that the flow area is constant along this passage. The turbine system has guide vanes before and behind the rotor so as to operate efficiently in reciprocating airflow. They are set by pivots on the shroud casing wall as shown in Figure 2. The pivots are located at the end of the guide vane chord close to the rotor. The pitch angles of guide vanes are controlled by the stepping motors, timing pulleys, and timing belts. Each cascade of outer and inner guide vanes changes the pitch angle simultaneously when the airflow direction changes. These guide vanes rotate between nozzle setting angle (upstream side of the rotor) and diffuser setting angle (downstream side), that is, $\theta_{\mathrm{ni}}$ and $\theta_{\mathrm{di}}$ for inner guide vanes, and $\theta_{\mathrm{no}}$ and $\theta_{\mathrm{do}}$ for outer guide vanes, as shown in Figures 3 and 4 , where $V_{R}$ and $T$ are the maximum velocity and period of sinusoidal airflow, respectively.

The geometries of the guide vane are shown in Figure 3. The guide vane consists of a straight line and circular arc. Details of the guide vane are given by chord length of $50 \mathrm{~mm}$; solidity of inner guide vane at $r_{R}$ of 1.15; and solidity of outer guide vane of 1.16 . The nozzle setting angle is only $15^{\circ}$ for both the airflow directions, that is, $\theta_{\mathrm{ni}}=\theta_{\mathrm{no}}=15^{\circ}$. In order to clarify the effect of the diffuser setting angle on the turbine characteristics, the range of $\theta_{\mathrm{di}}$ is from $20^{\circ}$ to $60^{\circ}$ for the inner guide vanes in the case of inhalation, and the 


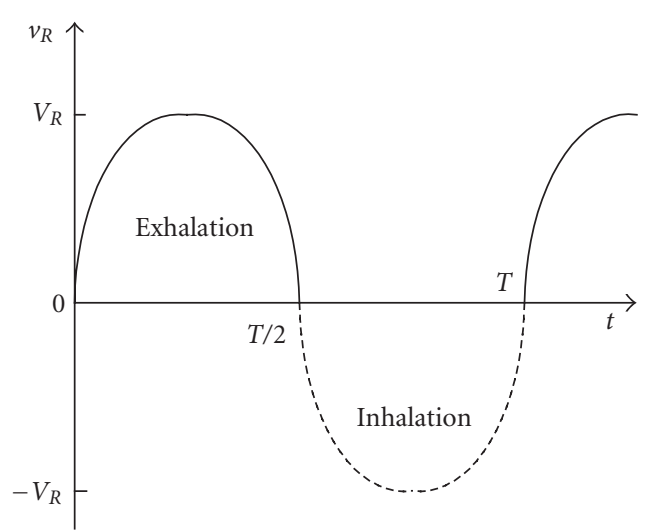

(a)



(b)

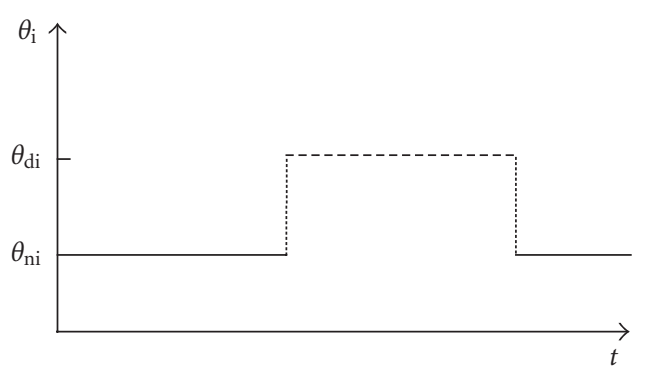

(c)

FIGURE 4: Behavior of pitch-controlled guide vanes. (a) Radial flow velocity. (b) Pitch angle of outer guide vane. (c) Pitch angle of inner guide vane.

range of $\theta_{\mathrm{do}}$ is from $30^{\circ}$ to $90^{\circ}$ for the outer guide vanes in the case of exhalation. The geometry of rotor blade is shown in Figure 5 and is the same as that used in previous studies (Setoguchi et al. [6, 8, 9]; Takao et al. [7]). The blade profile consists of a circular arc on the pressure side and part of an ellipse on the suction side. The ellipse has semimajor axis of $125.8 \mathrm{~mm}$ and semi-minor axis of $41.4 \mathrm{~mm}$. Detailed information about the blade profile is as follows: chord length of $54 \mathrm{~mm}$; tip clearance of $1 \mathrm{~mm}$; mean radius of $r_{R}=217.4 \mathrm{~mm}$; blade inlet (or outlet) angle of $60^{\circ}$; thickness ratio of 0.3 . The blade is oriented such that the blade profile is tangent to a radial line at the maximum thickness point on the suction side which can be seen clearly for the second blade from the left in Figure 3.

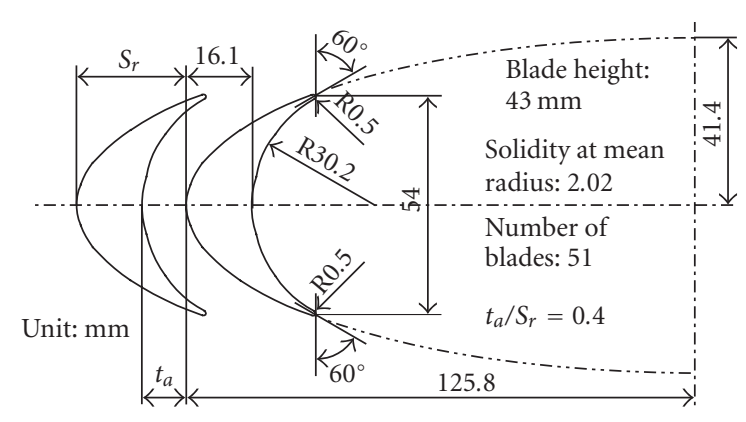

FIGURE 5: Rotor blade.

\section{EXPERIMENTAL RESULTS AND DISCUSSIONS}

\subsection{Turbine characteristics under steady flow conditions}

As the first step to an analysis of the new radial turbine, the turbine characteristics under steady flow conditions have been clarified in this section. Experimental results on the running characteristics of the turbine are expressed in terms of the torque coefficient $C_{T}$, input coefficient $C_{A}$, and efficiency $\eta$, which are all plotted against the flow coefficient $\phi$. The various definitions are

$$
\begin{gathered}
C_{T}=\frac{T_{o}}{\left\{\rho\left(v_{R}^{2}+U_{R}^{2}\right) A_{R} r_{R} / 2\right\}}, \\
C_{A}=\frac{\Delta p Q}{\left\{\rho\left(v_{R}^{2}+U_{R}^{2}\right) A_{R} v_{R} / 2\right\}}=\frac{\Delta p}{\left\{\rho\left(v_{r}^{2}+U_{R}^{2}\right) / 2\right\}},
\end{gathered}
$$

where $\rho$ and $U_{R}$ are density of air, and rotational speed at $r_{R}$, respectively. Efficiency, which is the ratio of shaft power output to pneumatic power input, can be expressed in terms of the coefficients mentioned above:

$$
\eta=\frac{T_{o} \omega}{\Delta p Q}=\frac{C_{T}}{C_{A} \phi} .
$$

The flow coefficient is defined as

$$
\phi=\frac{v_{R}}{U_{R}}
$$

Figures 6 and 7 show the effect of diffuser setting angle of the inner guide vane on the turbine characteristics under steady flow conditions. The pitch angle is set at a particular value because tests are performed under steady flow conditions in the experiment. In Figure 6(c) the solid line represents the efficiency of the radial turbine with fixed guide vanes which has the optimum setting angle $\left(\theta_{\mathrm{i}}=\theta_{\mathrm{o}}=25^{\circ}\right)$ (Setoguchi et al. [6]; Takao et al. [7]). When the flow direction is from atmosphere to settling chamber (i.e., inhalation) the inner guide vane is downstream of the rotor and it works as a diffuser. Consequently, the torque coefficient $C_{T}$ is 




(a)

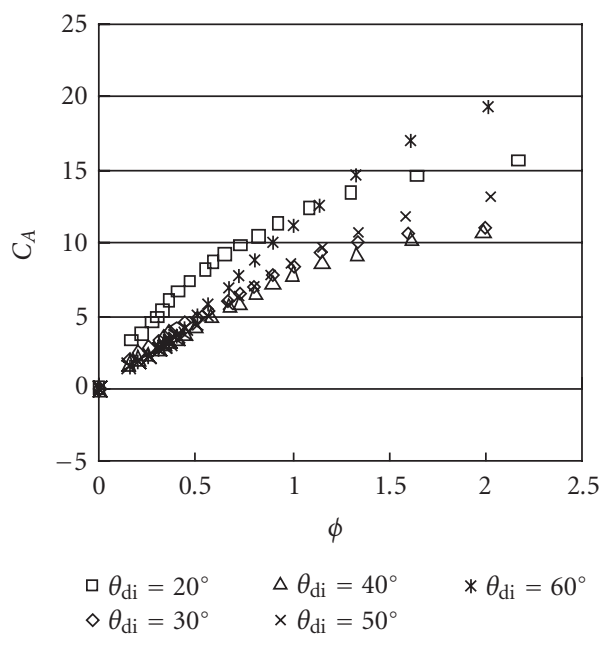

(b)

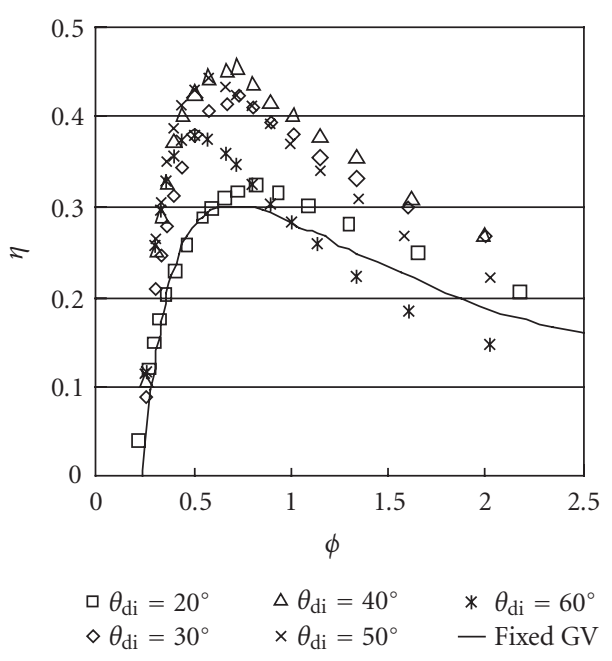

(c)

Figure 6: Effect of diffuser setting angle of inner guide vane on turbine characteristics (inhalation, $\theta_{\text {no }}=15^{\circ}$ ). (a) Torque coefficient. (b) Input coefficient. (c) Efficiency.

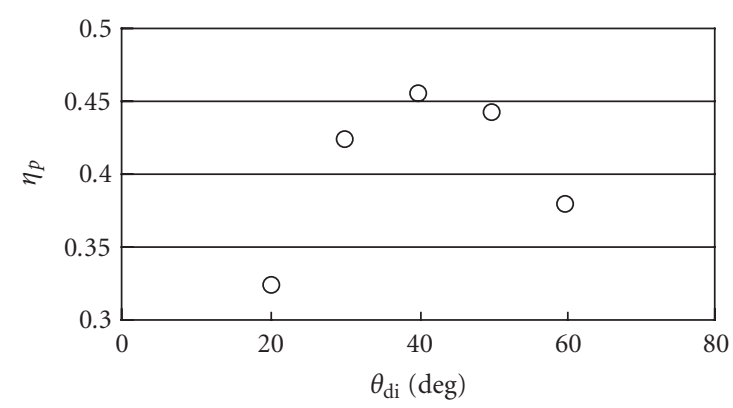

FIGURE 7: Effect of diffuser setting angle of inner guide vane on peak efficiency (inhalation, $\theta_{\mathrm{no}}=15^{\circ}$ ).

independent of $\theta_{\mathrm{di}}$ as shown in Figure 6(a), whereas the input coefficient $C_{A}$ decreases with increasing $\theta_{\mathrm{di}}$ for $\theta_{\mathrm{di}} \leq 40^{\circ}$ in Figure 6(b). Then, $C_{A}$ increases with $\theta_{\mathrm{di}}$ for $\theta_{\mathrm{di}} \geq 40^{\circ}$. Combining the above results and (2), it is evident that the highest efficiency occurs for the highest value of $\theta_{\mathrm{di}}=40^{\circ}$ and its value is approximately 0.45 when the flow is "from atmosphere" (Figures 6(c) and 7). Moreover, it can be observed from Figure 6(c) that the efficiency of the proposed radial turbine is higher than that of the conventional radial turbine (i.e., the radial turbine with fixed guide vanes) by 0.15 .

Conversely, Figures 8 and 9 show the effect of diffuser setting angle of the outer guide vane on the turbine characteristics under steady flow conditions. When the flow direction is from chamber to atmosphere (i.e., exhalation), the outer guide vane is downstream of the rotor and it works as a diffuser. Hence, the torque coefficient $C_{T}$ is independent of $\theta_{\text {do }}$ as shown in Figure 8(a). Regarding $C_{A}-\phi$ characteristics, in Figure 8(b) $C_{A}$ decreases slightly with increasing $\theta_{\mathrm{do}}$ for $\theta_{\mathrm{do}} \leq 60^{\circ}$ and $C_{A}-\phi$ characteristics in the case of $\theta_{\text {do }} \geq 60^{\circ}$ are almost the same. As a result, $\eta$ increases with $\theta_{\text {do }} \leq 60^{\circ}$ and remains in a stable situation at around 0.33 (Figures $8(\mathrm{c})$ and 9 ). Its efficiency is higher than that of the conventional radial turbine by 0.03 . Moreover, looking at the efficiency curves in Figures 6(c) and 8(c), it is seen that higher efficiencies are obtained when the flow is from atmosphere.

\subsection{Turbine characteristics under sinusoidal flow conditions}

Actually, air turbine for wave power conversion is operated under unsteady flow conditions since the airflow is generated by OWC. Therefore, it is inadequate to compare the performance of the proposed radial turbine with that of the conventional radial turbine under steady flow conditions. Here, investigations are made for the turbine characteristics under reciprocating flow conditions in order to clarify the usefulness of the proposed radial turbine and the effect of pitchcontrolled guide vanes on the turbine performance.

When the turbine is in the running condition, the parameters of turbine performance such as $T_{o}, Q, \Delta p$, and $\omega$ 




(a)

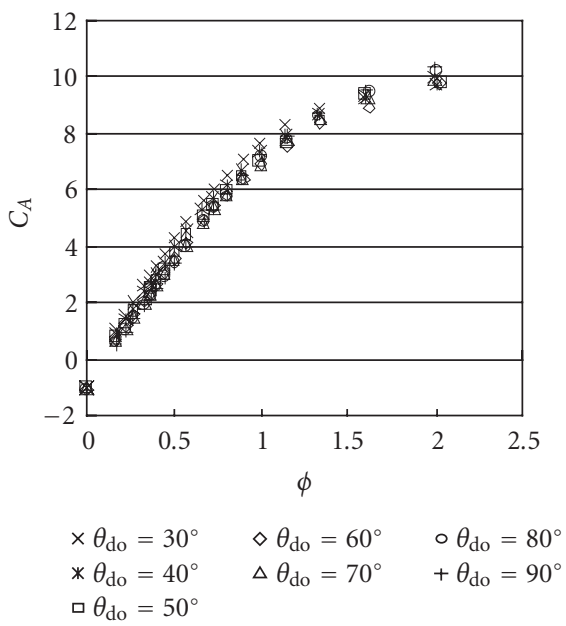

(b)

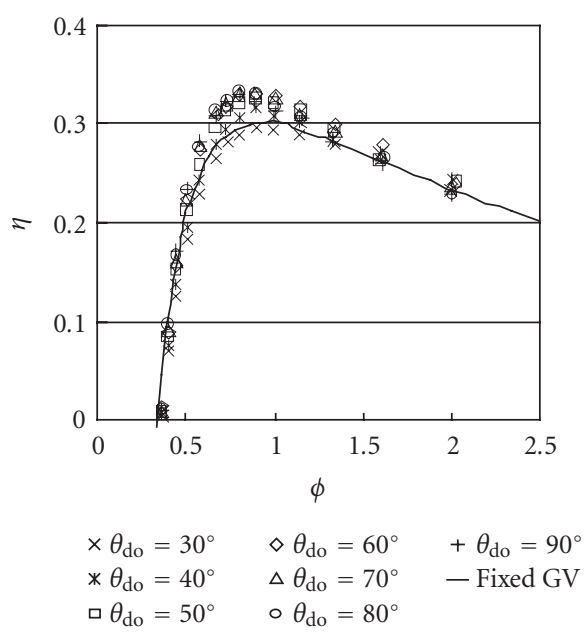

(c)

FIGURE 8: Effect of diffuser setting angle of outer guide vane on turbine characteristics (exhalation, $\theta_{\mathrm{ni}}=15^{\circ}$ ). (a) Torque coefficient. (b) Input coefficient. (c) Efficiency.

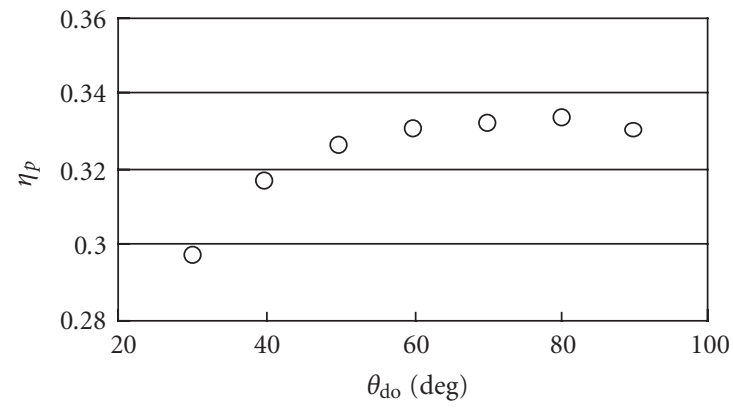

FIGURE 9: Effect of diffuser setting angle of outer guide vane on peak efficiency (exhalation, $\theta_{\text {ni }}=15^{\circ}$ ).

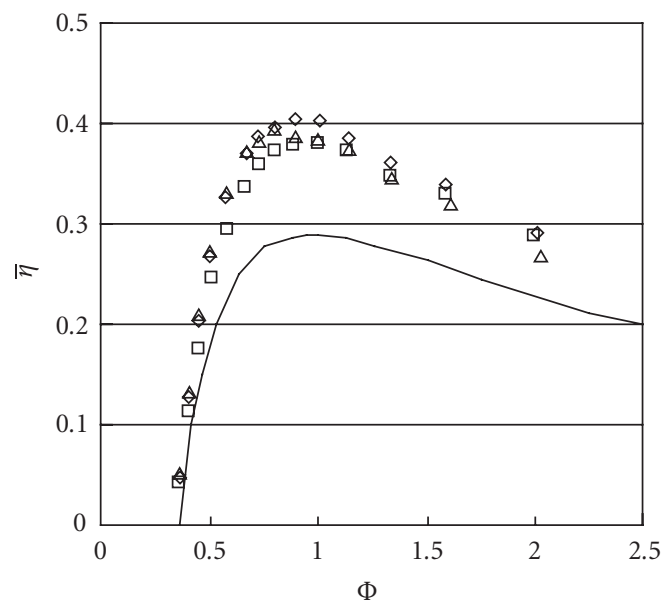

$$
\begin{array}{ll}
\square \theta_{\mathrm{di}}=30^{\circ}, \theta_{\mathrm{do}}=70^{\circ} & \Delta \theta_{\mathrm{di}}=50^{\circ}, \theta_{\mathrm{do}}=70^{\circ} \\
\diamond \theta_{\mathrm{di}}=40^{\circ}, \theta_{\mathrm{do}}=70^{\circ} \quad-\text { Fixed GV }
\end{array}
$$

(a)



(b)

Figure 10: Effect of diffuser setting angle of inner guide vane on turbine characteristics under sinusoidal flow conditions $\left(\theta_{\mathrm{ni}}=\right.$ $\theta_{\text {no }}=15^{\circ}$ ). (a) Mean efficiency. (b) Peak efficiency.

vary periodically in a sinusoidal oscillating flow. In this case, turbine performance should be represented by mean value. The running characteristics are evaluated in the relationship between the mean efficiency $\bar{\eta}$ and the flow coefficient $\Phi$ 


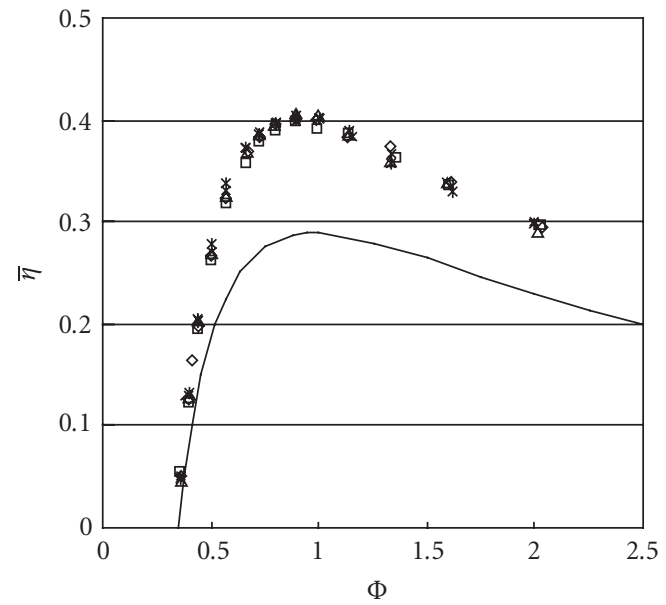

$$
\begin{array}{ll}
\triangle \theta_{\mathrm{di}}=40^{\circ}, \theta_{\mathrm{do}}=50^{\circ} & \times \theta_{\mathrm{di}}=40^{\circ}, \theta_{\mathrm{do}}=80^{\circ} \\
\diamond \theta_{\mathrm{di}}=40^{\circ}, \theta_{\mathrm{do}}=60^{\circ} & * \theta_{\mathrm{di}}=40^{\circ}, \theta_{\mathrm{do}}=90^{\circ} \\
\Delta \theta_{\mathrm{di}}=40^{\circ}, \theta_{\mathrm{do}}=70^{\circ} & - \text { Fixed GV }
\end{array}
$$

(a)

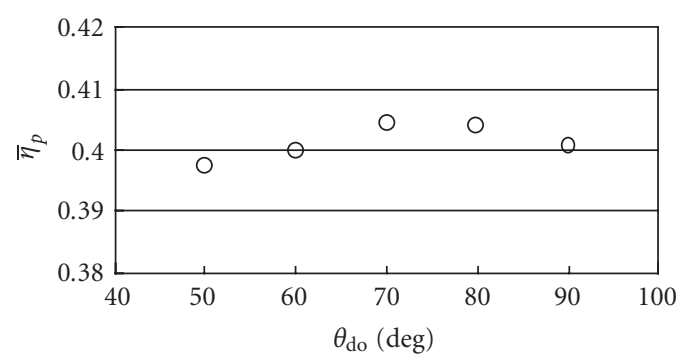

(b)

Figure 11: Effect of diffuser setting angle of outer guide vane on turbine characteristics under sinusoidal flow conditions $\left(\theta_{\mathrm{ni}}=\right.$ $\theta_{\text {no }}=15^{\circ}$ ). (a) Mean efficiency. (b) Peak efficiency.

defined as

$$
\begin{gathered}
\bar{\eta}=\frac{(1 / T) \int_{0}^{T} T_{o} \omega d t}{(1 / T) \int_{0}^{T} \Delta p Q d t}, \\
\Phi=\frac{V_{R}}{U_{R}},
\end{gathered}
$$

where $\bar{\eta}$ is evaluated over one wave period (see Figure 4) with the rotor rotating at constant speed and $V_{R}$ is the amplitude of the radial velocity of sinusoidal airflow.

Figures 10 and 11 show the effect of setting angles of inner and outer guide vanes on the mean efficiency under sinusoidal oscillating flow conditions. As is evident from Figures $10(\mathrm{~b})$ and 11(b), the highest efficiency was obtained in case of the combination of $\theta_{\mathrm{di}}=40^{\circ}$ and $\theta_{\mathrm{do}}=70^{\circ}$. The cause of the above result may be understood by considering the turbine characteristics under steady flow conditions
(Figures 6 and 8). Furthermore, the efficiency of the new radial turbine is higher than that of the conventional radial turbine by approximately 0.11 as shown in Figures 10(a) and 11(a).

Therefore, it has been concluded from the above results that the performance of the radial turbine can be improved considerably by using pitch-controlled guide vanes.

\section{CONCLUSIONS}

In order to develop a high-performance radial turbine for wave power conversion, a radial turbine with pitchcontrolled guide vanes has been proposed and investigated experimentally by model testing. The experiment has been carried out under steady and sinusoidal flow conditions in the study. Then, the results have been compared with those of a radial turbine with fixed guide vanes.

As a result, the performances of the proposed radial turbine under steady and sinusoidal flow conditions have been clarified. Furthermore, it seems that the proposed radial turbine is much superior to the conventional radial turbine, that is, the radial turbine with fixed guide vanes.

\section{ACKNOWLEDGMENT}

The first author wishes to thank the Shimane Industrial Promotion Foundation (SIPF) for the financial support which made this investigation possible.

\section{REFERENCES}

[1] K. Kaneko, T. Setoguchi, and S. Raghunathan, "Self-rectifying turbine for wave energy conversion," in Proceedings of 1st International Offshore Polar Engineering Conference (ISOPE '91), vol. 1, pp. 385-392, Edinburgh, Scotland, UK, August 1991.

[2] K. Kaneko, T. Setoguchi, and S. Raghunathan, "Self-rectifying turbines for wave energy conversion," International Journal of Offshore and Polar Engineering, vol. 2, no. 3, pp. 238-240, 1992.

[3] M. E. McCormick, J. G. Rehak, and B. D. Williams, "An experimental study of a bidirectional radial turbine for pneumatic wave energy conversion," in Proceedings of Mastering the Oceans Through Technology (OCEANS '92), vol. 2, pp. 866-870, Newport, RI, USA, October 1992.

[4] M. E. McCormick and B. Cochran, "A performance study of a bi-directional radial turbine," in Proceedings of 1st European Wave Energy Conference, pp. 443-448, Edinburgh, Scotland, UK, July 1993.

[5] T. N. Veziroglu, Ed., Alternative Energy Sources VI, Vol. 3, Wind/Ocean/Nuclear/Hydrogen, Hemisphere, Washington, DC, USA, 1985.

[6] T. Setoguchi, S. Santhakumar, M. Takao, T. H. Kim, and K. Kaneko, "A performance study of a radial turbine for wave energy conversion," Journal of Power and Energy, vol. 216, no. A1, pp. 15-22, 2002.

[7] M. Takao, K. Itakura, T. Setoguchi, T. H. Kim, K. Kaneko, and A. Thakker, "Performance of a radial turbine for wave power conversion," in Proceedings of the 12th International Offshore and Polar Engineering Conference (ISOPE '02), vol. 1, pp. 562-567, Kitakyushu, Japan, May 2002. 
[8] T. Setoguchi, K. Kaneko, H. Taniyama, H. Maeda, and M. Inoue, "Impulse turbine with self-pitch-controlled guide vanes for wave power conversion," International Journal of Offshore Polar Engineering, vol. 6, no. 1, pp. 76-80, 1996.

[9] T. Setoguchi, M. Takao, Y. Kinoue, K. Kaneko, S. Santhakumar, and M. Inoue, "Study on an impulse turbine for wave energy conversion," International Journal of Offshore Polar Engineering, vol. 10, no. 2, pp. 145-152, 2000. 



Submit your manuscripts at

http://www.hindawi.com
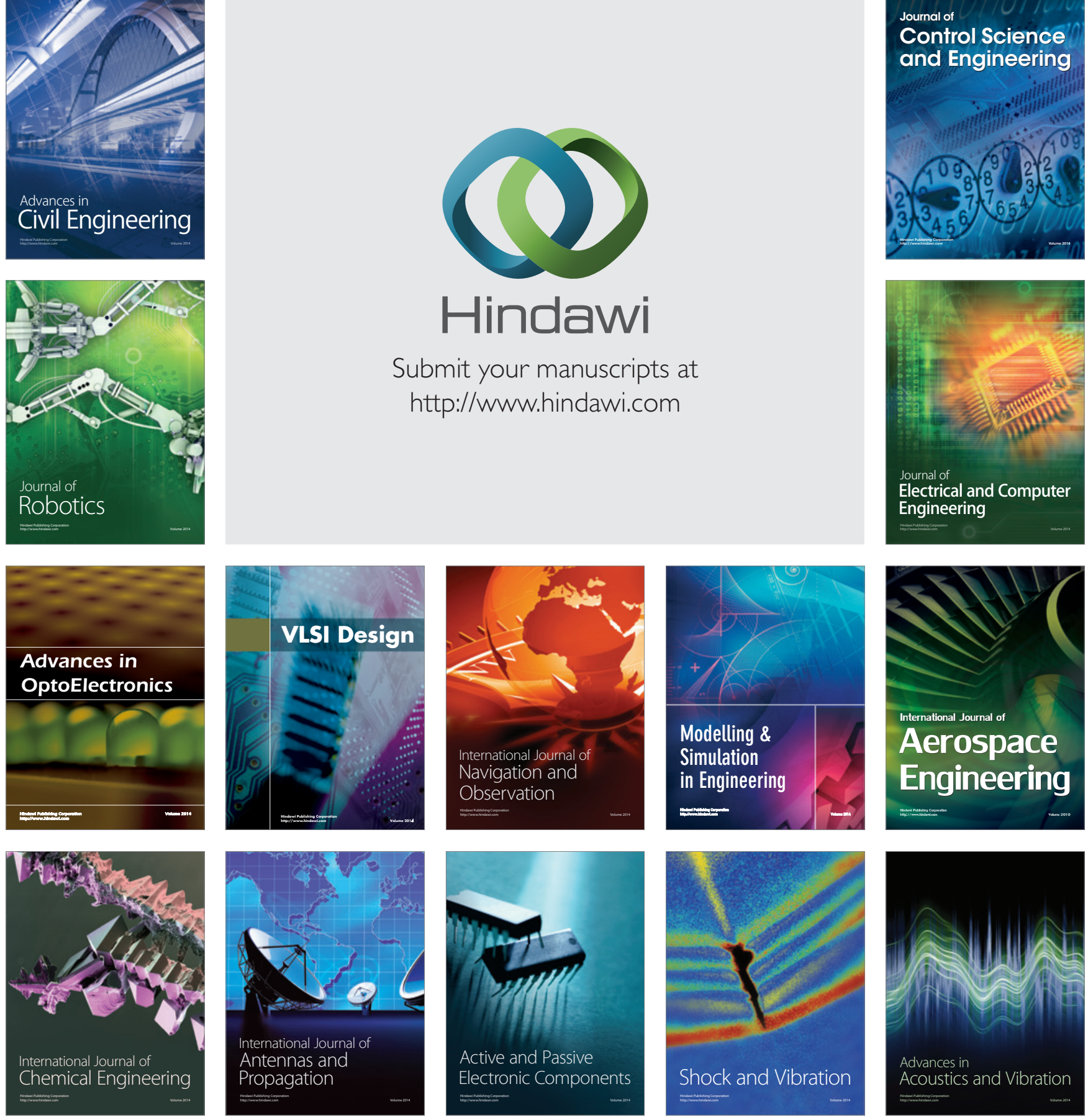